\title{
Fatigue Responses of Three AA 2000 Series Aluminum Alloys
}

\author{
Gbadebo Moses Owolabi', Mark Thom¹, Olusegun Ajide ${ }^{1,2}$, Nikhil Kumar', \\ Amin Azimi $^{*}$ (D), Horace Whitworth ${ }^{1}$, Grant Warner ${ }^{1}$ \\ ${ }^{1}$ Department of Mechanical Engineering, Howard University, Washington DC, USA \\ ${ }^{2}$ Department of Mechanical Engineering, University of Ibadan, Ibadan, Nigeria \\ Email: ^amin.azimi@howard.edu, ^aminazimi.kntu@gmail.com
}

How to cite this paper: Owolabi, G.M., Thom, M., Ajide, O., Kumar, N., Azimi, A., Whitworth, H. and Warner, G. (2019) Fatigue Responses of Three AA 2000 Series Aluminum Alloys. Journal of Materials Science and Chemical Engineering, 7, 32-48. https://doi.org/10.4236/msce.2019.73003

Received: February 17, 2019

Accepted: March 24, 2019

Published: March 27, 2019

Copyright ( 2019 by author(s) and Scientific Research Publishing Inc. This work is licensed under the Creative Commons Attribution International License (CC BY 4.0).

http://creativecommons.org/licenses/by/4.0/

\section{(c) (i) Open Access}

\begin{abstract}
In this paper, smooth specimens of three aluminum alloys: AA 2219-T8, AA 2519-T8 and AA 2624-T351, were subjected to the same level of uniaxial (tension/compression) fatigue loading to compare their fatigue responses. Fractographic investigations of the failed specimens after fatigue loading was also conducted using a scanning electron microscope. The fatigue test results showed considerable differences in the fatigue lives of the three investigated alloys with AA 2219-T8 having the shortest fatigue life and AA 2624-T351 the longest fatigue life. The fractographic analysis showed that coalescence of micropores, microvoids, particles cleavage and microcracks are the predominant features in the fracture surface of AA 2219-T8. The fracture surface features of AA 2519-T8 revealed higher resistance to fatigue cracks nucleation and growth when compared to AA 2219-T8. The features depicted mainly partly ductile and partly brittle fracture. The AA 2624-T351 fracture surface features revealed noteworthy ductile failure mechanism. The results suggest a strong correlation between the surface fractographic features and the fatigue lives of the alloys. It is also observed that in addition to the yield strengths and ultimate tensile strengths, the total strain energy densities (SED) may provide a reasonable indication of the relative fatigue performance of the three alloys. AA 2219-T8 had the lowest SED and the lowest fatigue life, while AA 2624-T351 had the highest SED and the highest fatigue life. Thus, AA 2624-T351 would be the most suitable materials for components subjected to fatigue loading.
\end{abstract}

\section{Keywords}

Fatigue Life, Aluminum Alloy, Strain Energy Density, Fractography

\section{Introduction}

Remarkable progress has been made over the past few decades in the develop- 
ment of high performance aluminum alloys. Aluminum alloys have a proven 70-year record of continuously improvement in terms performance and production cost [1]. The benefits of these alloys include their high specific strength, excellent corrosion resistance, high fracture toughness and fatigue crack growth resistance [2]-[8]. The high strength-to-weight ratio of aluminum alloys makes them choice materials in air and spacecraft where their low density translates to increased fuel efficiency and reduction in green gas emissions [9] [10] [11] [12].

Fatigue is critical to the structural integrity of aluminum alloys. Laudable efforts have been made on studies that focused on the fatigue behavior of aluminum alloys. The research investigations conducted recently by Xue et al. [13] on the fatigue life of aging aircraft have invigorated research activities on the formation, detection and estimation of fatigue damage on high strength aluminum alloys. The authors asserted that the determinations of fatigue life and cracks size and crack growth rates are critical for strategic safety evaluation process. Fatigue has been identified by Gupta and Agnew to pose a serious threat to service lives of critical components in aero structures [14]. The fatigue response of Al 2024 T3 laser machined sheets was investigated by Carpio et al. [15]. Results obtained by the authors revealed that the laser machined experimental data are very close to aeronautic requirements for fatigue resistance. However, the predicted theoretical or intrinsic material fatigue resistance was estimated to be significantly higher than the obtained laser machined experimental data. The observed variations were attributed to the surface roughness of the heat affected zone (HAZ), thus promoting crack initiations. In the concluding remark of the paper, it was suggested that the surface roughness as well as the fatigue resistance of the alloy can be enhanced by using higher power and high absorption wavelength (such as $\lambda=1.06 \mu \mathrm{m}$ ). Desmukh et al. [16] investigated the influence of scandium alloying addition on the fatigue response of 7010 aluminum alloy. The study revealed that addition of scandium refines the grain structure of the alloy, but yielded poor fatigue crack growth resistance and fatigue thresholds. Very long-life fatigue and near threshold fatigue crack growth response of 7075 and 6061 aluminum alloys in T6 condition were investigated by Wang et al. [17]. The experimental results show that both alloys can withstand fatigue fracture beyond $10^{7}$ cycles at $210 \mathrm{MPa}$ and $140 \mathrm{MPa}$ for Al-alloys 7075 and 6061, respectively. In addition, the authors observed no evidence of endurance limit in the two alloys until $10^{9}$ cycles (at approximately $195 \mathrm{MPa}$ and $90 \mathrm{MPa}$ for 7075 and 6061, respectively). It was found that the fatigue strength of 7075 alloy is higher than that of 6061, even in the super long life region. Their study also revealed superior fatigue properties of 7075 in comparison with 6061, and could be attributed to the higher tensile strength of the $7075 \mathrm{Al}$-alloy. The authors were able to establish that the fatigue crack growth rates of small cracks in the investigated alloys were found to be greater than those of large cracks for the same stress intensity factor range. The fractographic analysis revealed that substantial void nucleation occurred in the two aluminum alloys in early stage of fatigue crack propagation. During high crack growth rates, the observed voids were insignificant while stri- 
ations became obvious. Ceschini et al. [18] studied the influence of Hot Isostatic Pressing (HIP) on the fatigue response of sand-cast A356-T6 and 204-T6 aluminum alloys. Findings from this study revealed that HIP process led to immense reduction in fatigue resistance by about $40 \%$ for A356 and 70\% for A204. It was also reported that the non-HIP processed A204 alloy showed slightly lower fatigue resistance than A356, which was attributed to the presence of many shrinkage cavities along grain boundaries.

Sharma et al. [19] examined the fatigue response of AA 2219 under different aging conditions. They reported that the alloy in naturally aged condition exhibited the highest resistance to fatigue cracks initiation. This was followed by fatigue responses of the under aged, peak aged and over aged conditions in that order. The crack growth rate increased while the near threshold stress intensity range decreased with advancing aging conditions. The fracture morphology was observed to experience immense changes from crystallographic facets near the threshold region to region of well-developed ductile striations. Zheng et al. [20] investigated the fatigue behavior of AA 2524-T34 alloys and reported that the fatigue crack initiation and propagation in AA 2524-T34 alloy was dramatically influenced by the presence of second phase particles. The deflection of cracks showed clear crystallographic features, which in turn implies that grain orientation plays a significant role in controlling fatigue crack propagation in the alloy.

Ma et al. [21] studied the mechanical properties and fatigue crack growth rates in Friction Stir Welded (FSW) nugget of 2198-T8 Al-Li alloy joints. Fatigue tests under different stress ratio $(\mathrm{R})$ were performed on the welded nugget and the parent material. Results showed that the fatigue crack growth rates in the nugget are not like the parent material that is sensitive to stress ratio. In addition, striations on the fracture surfaces were observed in the welded nugget. The fracture surface 2524 aluminum alloy that failed under fatigue loading revealed that the fatigue cracks in this alloy nucleated either on second phase particles or the interface between these particles and the continuous aluminum-rich phase [22]. The observed fracture mechanism consists of microcracks initiation and growth, and merging of microcracks. Yan and Fan [22] have also reported that the direction of microcrack propagation can be influenced by grain boundary. The effect of grain size on the fatigue crack growth in 2524-T3 alloy was examined by Shou et al. [23]. They observed that alloys with grain sizes in the range of $50-100 \mu \mathrm{m}$ to exhibit higher fatigue crack growth rates. Fractography examinations revealed that fatigue cracks propagated in a more tortuous manner in the alloy with grain sizes within the range $50-100 \mu \mathrm{m}$. Wu et al. [24] investigated the fatigue behavior of an $\mathrm{Al}-\mathrm{Cu}-\mathrm{Li}$ and observed that grain boundaries could not impede the fatigue crack growth due to coarse second phase particles present along the grain boundaries. The propagation of fatigue cracks along grain boundaries reduces the resistance to fatigue crack propagation. Ovono et al. [25] investigated the effect of aging treatment and alloying addition on the fatigue response of A319 and AS9U3G alloys in T5 condition. Results obtained by the authors showed that increase in volume fraction of the alloying elements affected the fatigue life 
of AS9U3G alloy considerably when compared to that of A319. It was also reported that aging at $320^{\circ} \mathrm{C}$ for $100 \mathrm{~h}$ yielded notable increase in the fatigue lives of the two investigated alloys.

Takahashi et al. [26] studied the mechanism surrounding the growth characteristics of microcracks inherent in the Al-Mg-Si 6061-T6 alloy in the high cycle fatigue regime and reported that at a low stress level, over $90 \%$ of the total fatigue life was characterized by the growth of microcracks. The microcrack was found to be halted after more than $10^{6}$ cycles to failure and for a long period. After this long period, it began to grow again, which resulted in a significantly slow growth process. Fatigue crack growth response of Friction Stir Welded (FSW) AA 7075-T651 aluminum joint was studied by Sivaraj et al. [27]. The study was carried out using Center Cracked Tensile (CCT) specimens extracted from the FSW joints and that of unwelded material (as-received condition). The outcome of the study showed clearly that the fatigue life of the FSW AA 7075-T651 aluminum alloy suffered a considerable reduction in comparison with the unwelded as-received alloy. The authors attributed the dissolution of the precipitates in the weld region during the friction stir welding as the main cause of fatigue life reduction. The influence of heat treatment and surface quality on the fatigue life of Selective Laser Melting (SLM) produced AlSi10Mg has been examined by Aboulkhair et al. [28]. The study showed that a carefully conducted heat treatment significantly enhanced the fatigue response of the alloy. At $94 \mathrm{MPa}$ stress level, the heat-treated samples survived beyond the nominal fatigue life of $3 \times 10^{7}$ cycles of the as-produced SLM AlSi10Mg alloy. Szusta and Seweryn [29] investigated the low cycle fatigue (LCF) behavior of EN AW-2024-T3 at elevated temperatures under multiaxial loading. It was observed that fatigue life of EN AW 2024-T3 aluminum alloy increased as the phase shift between progressions of tensile and torsional loading increased at elevated temperatures. Wang et al. investigated the effects of Laser Shock Peening on high temperature fatigue response of 7075 aluminum alloy [30] using a load frequency of $30 \mathrm{~Hz}$ and a load ratio $\mathrm{R}=0.1$. The authors reported that the high temperature fatigue life of the specimens after laser shock peening treatment exhibited $20 \%$ and $110 \%$ enhancement at $200^{\circ} \mathrm{C}$ and $150^{\circ} \mathrm{C}$, respectively when compared with those without treatment. However, the emergence of gradual reductions in fatigue life commenced at $250^{\circ} \mathrm{C}$. Many other works [31]-[40] have further enriched literature on the fatigue life of aluminum based alloys.

Enormous research efforts have been made on the study of fatigue lives of 2000 series aluminum alloys. The influence of heat treatment and anodization on fatigue life of 2017A alloy was investigated by Hemmouche et al. [41]. The outcome of the tests showed a decrease in fatigue life of anodized specimens as compared to the untreated ones. The nature of oxide layer and heterogeneous microstructures of the film was reported to cause the observed decrease in the fatigue life of the alloy. The effect of strain ratio and microstructural features on the fatigue response of 2124-T851 aluminum alloy (with smooth surface) during low cycle fatigue was investigated by Hao et al. [42]. The observed microstruc- 
tural features revealed that density and length of slip bands influences the magnitude of strain ratios. The authors showed that the higher density and larger length of slip bands led to larger strain ratios at the strain amplitude of $0.6 \%$. It was also shown that at larger strain ratios, volume fraction and size of coarse constituents increases. The aftermath of these changes in microstructures were attributed to the reduction in fatigue life of the material. Fares et al. investigated the coupled effect of substrate microstructure and sulphuric process anodizing on the fatigue performance of a 2017A-T4 aluminum alloy [43]. At high alternating stresses, the existence of the anodic film has no pronounced effect on fatigue crack growth of the alloy for both microstructural conditions. Nevertheless, the results obtained at low alternating stresses revealed that anodizing significantly reduces the fatigue life of the alloy for both microstructural conditions. This reduction in fatigue life was attributed to the preferential dissolution of the matrix around the cathodic particles (such as $\mathrm{Al}_{2} \mathrm{Cu}$ ). This led to the formation of cavities which acted as stress concentrators thus promoting the nucleation of several fatigue microcracks. A comparative study of the fatigue response of AA 2198-T8 and AA 2024-T3 was considered by Stanley et al. [44]. Fatigue fracture surface morphology was examined. Fractography results shows that AA 2024-T3 exhibited significant twisting fracture surface with localized fatigue crack growths along many directions. Whereas the fracture surface of the AA 2198-T8 was observed by the authors to be characterized with evenly distributed but shallow striations. It was concluded that AA 2198-T8 showed a better fatigue resistance. Jayaraman et al. [45] studied the possibility of improving the fatigue life of Friction Stir Welded (FSW) joint of 2219-T8751 aluminum alloy. The presence of compressive residual stress on the surface of FSW joint has been identified to pose a detrimental effect on the fatigue life of the alloy. A recently developed technique, Low Plasticity Burnishing (LPB), was employed to introduce a deep surface layer on the FSW joint. Fatigue life of FSW joint with LPB and without LPB was estimated. It was found that the FSW joint with LPB had higher fatigue life than the FSW joint without LPB. The outcome of this study reinforces the authors' hypothesis that the presence of compressive residual stress on the surface of FSW joint can affect its fatigue life. Xu et al. performed strain-controlled cycle fatigue tests on FSW 2219-T62 aluminum at different welding parameters and cooling conditions [46]. Experimental results indicated a slight decrease in fatigue life of the alloy as welding speed was increased from 60 to $200 \mathrm{~mm} / \mathrm{min}$. In addition, FSW joints with water cooling condition experienced a higher fatigue life than that with air cooling condition.

Among the 2000 series aluminum alloys, the choice of AA 2219-T8, AA 2519-T8 and AA 2624-T351 are gaining more prominent research interests for application in aerostructures applications. Notwithstanding, not much work has been done that focused on the fatigue behavior of AA 2219-T8, AA 2519-T8 and AA 2624-T351 aluminum alloys. The main objective of this paper is to provide experimental data on the fatigue response of these alloys and compare their behavior fatigue loading condition. 


\section{Materials and Experimental Methods}

\subsection{Fatigue Tests}

The three aluminum alloys investigated in this work are AA 2219-T8, AA 2519-T8 and AA 2624-T351. The main alloying element in each of these alloys is copper. The approximate percentages of alloying elements in each of the alloys are presented in Table 1. Tensile tests were also conducted on the samples from the same alloys in order to correlate the mechanical properties under quasi-static loading with the fatigue lives of the alloys.

The fatigue test specimens were machined according to ASTM E466-15 [47] standard as presented in Figure 1. Force-controlled loads were applied to the fatigue test specimens, in which each specimen was subjected to nominal stress

Table 1. Approximate percentage of the alloying elements.

\begin{tabular}{cccc}
\hline Elements & AA 2219 & AA 2519 & AA 2624 \\
\hline Aluminum, $\mathrm{Al}$ & $91.5 \%-93.8 \%$ & $91 \%-94.4 \%$ & $92.79 \%-94.55 \%$ \\
Chromium, $\mathrm{Cr}$ & - & - & $\leq 0.05 \%$ \\
Copper, $\mathrm{Cu}$ & $5.8 \%-6.8 \%$ & $5.3 \%-6.4 \%$ & $3.8 \%-4.3 \%$ \\
Iron, $\mathrm{Fe}$ & $\leq 0.30 \%$ & $\leq 0.30 \%$ & $\leq 0.08 \%$ \\
Magnesium, $\mathrm{Mg}$ & $\leq 0.02 \%$ & $0.05 \%-0.40 \%$ & $1.2 \%-1.6 \%$ \\
Manganese, $\mathrm{Mn}$ & $0.20 \%-0.40 \%$ & $0.10 \%-0.50 \%$ & $0.45 \%-0.70 \%$ \\
Si $+\mathrm{Fe}$ & - & $\leq 0.40 \%$ & - \\
Silicon, $\mathrm{Si}$ & $\leq 0.20 \%$ & $\leq 0.25 \%$ & $\leq 0.08 \%$ \\
Titanium, $\mathrm{Ti}$ & $0.02 \%-0.10 \%$ & $0.02 \%-0.10 \%$ & $\leq 0.10 \%$ \\
Vanadium, V & $0.05 \%-0.15 \%$ & $0.05 \%-0.15 \%$ & - \\
Zinc, $\mathrm{Zn}$ & $\leq 0.10 \%$ & $\leq 0.10 \%$ & $\leq 0.15 \%$ \\
Zirconium, $\mathrm{Zr}$ & $0.10 \%-0.25 \%$ & $0.10 \%-0.25 \%$ & - \\
Other, total & $\leq 0.15 \%$ & $\leq 0.15$ & $\leq 0.15 \%$ \\
\hline
\end{tabular}

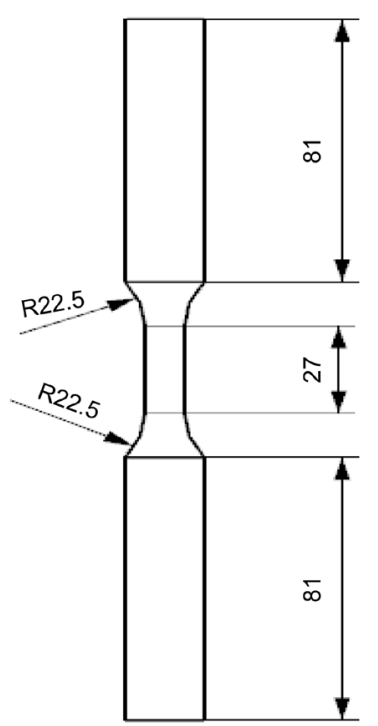

Figure 1. Geometry of fatigue the test specimen (dimensions in $\mathrm{mm}$ ). 
amplitude of approximately $246 \mathrm{MPa}$. The nominal stress amplitude was kept constant for each specimen in order to provide a basis for comparison of the performance of each tested alloy. Given the nominal diameter of the specimen, the amplitude of force on the specimens was $15.6 \mathrm{kN}$. The testing frequency was $1 \mathrm{~Hz}$ and the stress ratio (R) was -1 . The fatigue experiments were conducted on the MTS 809 Axial/Torsional Test System following ASTM E606/E606M-12 [48] standard. The MTS 809 Axial/Torsional is a servo hydraulic system which provides a maximum axial load of $250 \mathrm{kN}$ and a maximum torsional load of $2200 \mathrm{Nm}$. Tensile tests were also conducted on samples from the same alloys in order to correlate the mechanical properties under quasi-static loading with the fatigue lives of the alloys.

\subsection{Fractographic Examinations}

Cutting of the required fatigue fracture samples for fractographic examinations was done using high performance tabletop Struers Secotom-15 machine (with rotational speed range: $300-5000 \mathrm{rpm}$ ). Fracture surfaces of fractured specimens were investigated with the aid of Scanning Electron Microscope, SEM (TESCAN XEIA3).

\section{Results and Discussion}

\subsection{Tensile Results}

The results of tensile tests are presented in Table 2 and their stress-strain curves are illustrated in Figure 2. It can be seen that the AA 2219-T8 alloy has the lowest yield strength of $288 \mathrm{MPa}$, while AA 2519-T8 has the highest yield strength of $421 \mathrm{MPa}$. AA 2624-T351 has a yield strength of $374 \mathrm{MPa}$. Table 2 also shows that AA 2219-T8 has the lowest ultimate tensile strength (UTS) of the three alloys with a UTS of $299.54 \mathrm{MPa}$. AA 2519.T8 and AA 2624-T351 have very similar UTS of 463 and $467 \mathrm{MPa}$, respectively. The distinction between yield and ultimate strengths indicates lower strain hardening phenomenon in AA 2219-T8 than the two other alloys. However, this microstructure modification is highest in AA 2624-T351 which makes this alloy stronger than other samples. The Young's modulus (E), Elongation $(\varepsilon)$, Poisson's ratio $(v)$ and Strain Energy Density (SED) for the three alloys are also included in Table 2. These parameters

Table 2. Tensile properties of alloys.

\begin{tabular}{cccc}
\hline Property & AA 2219-T8 & AA 2519-T8 & AA 2624-T351 \\
\hline YS (MPa) & 288 & 421 & 374 \\
UTS (MPa) & 299 & 463 & 467 \\
E (GPa) & 75.8 & 67.9 & 72.8 \\
$\varepsilon$ & $10.6 \%$ & $10.0 \%$ & $19.0 \%$ \\
$v$ & 0.356 & 0.314 & 0.302 \\
SED & 34.31 & 43.45 & 85.09 \\
\hline
\end{tabular}




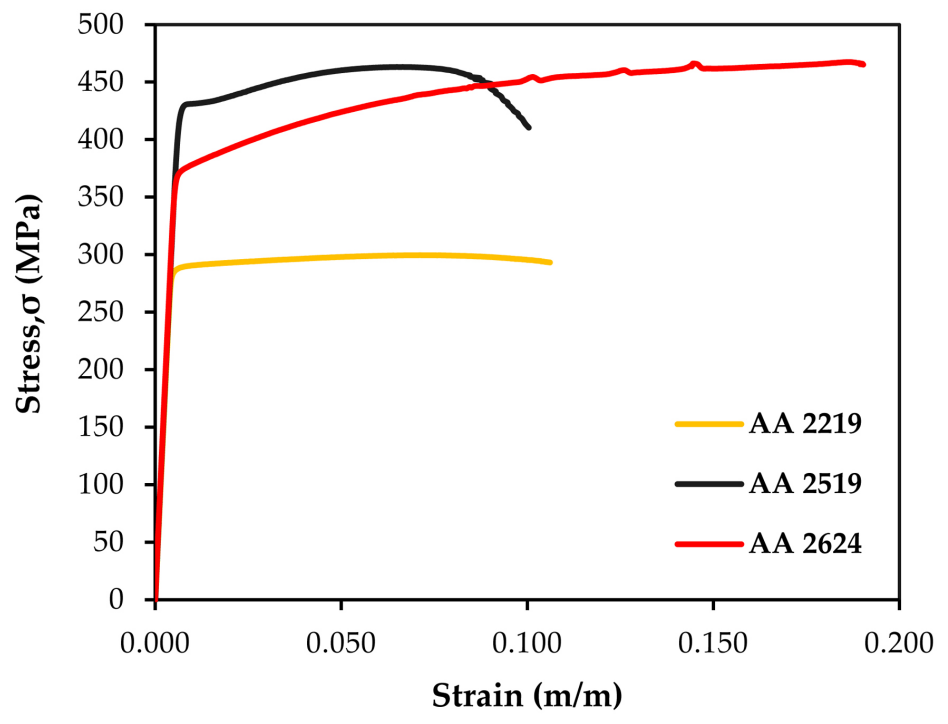

Figure 2. Stress-strain curve for the three alloys.

provide insights to the basic tensile characteristics of the three alloys investigated in this work. Poisson's ratio $(v)$ is the negative ratio of the transverse strain to the longitudinal strain for given material subjected to uniform longitudinal stress within the elastic deformation range. It is an elastic coefficient that provides insight into strength and ductility which are key design parameters for the investigated alloys. Strain energy density (SED) is a measure of the critical value that can provide insight into the fatigue life as well as macroscopic material failure criterion. The Young's modulus (E) is a measure of the stiffness of an elastic material in terms of ratio of stress to strain.

\subsection{Fatigue Test's Results}

The fatigue lives of the investigated smooth specimens for the three alloys are presented in Figure 3. AA 2219-T8 had the lowest fatigue life with 3787 cycles. The relatively low fatigue life of AA 2219-T8 was expected due to its being tested at 0.820 of its UTS (which is a significantly higher fraction of its UTS in comparison with the other two alloys). The fatigue life of AA 2519-T8 is 32196 cycles which is almost 9 times higher than that of AA 2219-T8 (see Figure 3). AA 2519-T8 was tested at 0.531 of its UTS while AA 2624-T351 was tested at 0.526 of its UTS. Notwithstanding, the fatigue life of AA 2624-T351 is 59540 cycles, which is nearly twice that of AA 2519-T8. Assessing the relative fatigue performances against relative tensile test performances of the alloys, a consistent relationship can be observed between the fatigue life and the strain energy density required (SED) for failure of the alloys in the tensile tests. The SED for failure of each of the alloy was determined using the area under their respective tensile stress-strain curves (Figure 1). SED for failure increases with fatigue life of the specimen. As illustrated in Figure 1 and Table 2, AA 2219-T8 had the lowest SED and lowest fatigue life, while AA 2624-T351 had the highest SED for failure and highest fatigue life. The use of strain energy density in fatigue life prediction 


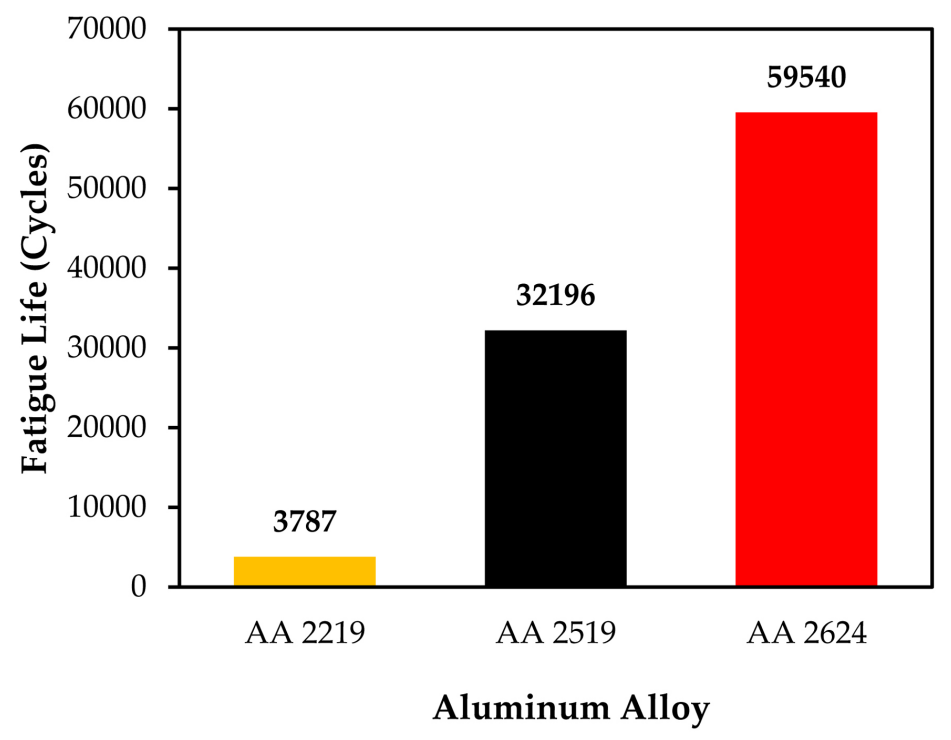

Figure 3. Bar chart showing average fatigue life for smooth specimens.

has been explored and proven to be satisfactory by Tang et al. [49].

\subsection{Fatigue Fracture}

Figures 4(a)-(c), Figures 5(a)-(c) and Figures 6(a)-(c) show the SEM fractographs of AA 2219-T8, AA 2519-T8 and AA 2624-T351, respectively. Although traces of dimples are observed in the fractograph of AA 2219-T8 as shown in Figure 4(a), the fracture surface features are characterized by the presence of macrocracks, microcracks, voids and micropores. These significant defects are marked by arrows in Figure 4. In Figure 4(b), the presence of particles cleavage, microvoids and microcracks are more prominent at the core of the fracture surface. Secondary phase particles can be observed on the fracture surfaces. There is also evidence of transgranular fracture on the surface failed specimen. In Figure 4 (c), both fine and coarse second phase particles are observed. The fracture morphologies of AA 2219-T8 illustrated in Figures 4(a)-(c) generally depicts ductile and brittle failure modes. However, from the analogy of Rambabu et al. [50], the coalescence of micropores, microvoids, particles cleavage, microcracks and random intermix are reminiscent of low resistance to fatigue cracks initiation and growth as well as brittle fracture failure mechanism. The features also portray fatigue transgranular fracture. The fracture surface of AA 2519-T8 in Figure 5(a) can be described as a combination of ridge-like and undulations-like structure containing pores, microcracks and voids that are not pronounced when compared to AA 2219-T8 in Figures 4(a)-(c). Fine particles are seen to be uniformly distributed in the alloy. For AA 2519-T8 (Figure 5(b)), the presence of fatigue striations can be observed on the fracture surface of this alloy, but more intense in the central core as well as X-marked regions of the fractograph. Secondary phase particles appeared to be scanty in the vicinity of striations but densely distributed in region $\mathrm{P}$ of the fractograph. There is also the presence of 

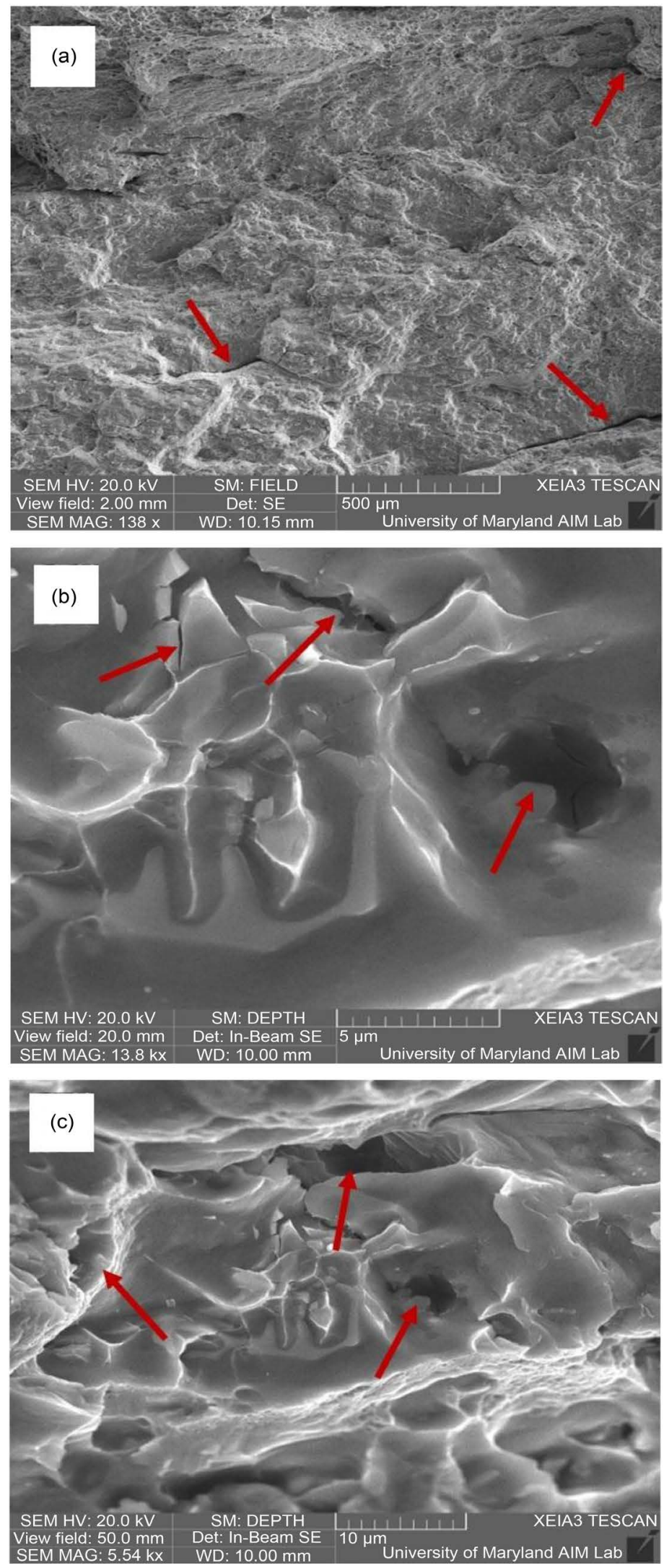

Figure 4. SEM Fatigue fracture surface of AA 2219-T8 (a) Magnification: 138x, (b) Magnification: 1.38 kx, and (c) Magnification: 5.54 kx. 

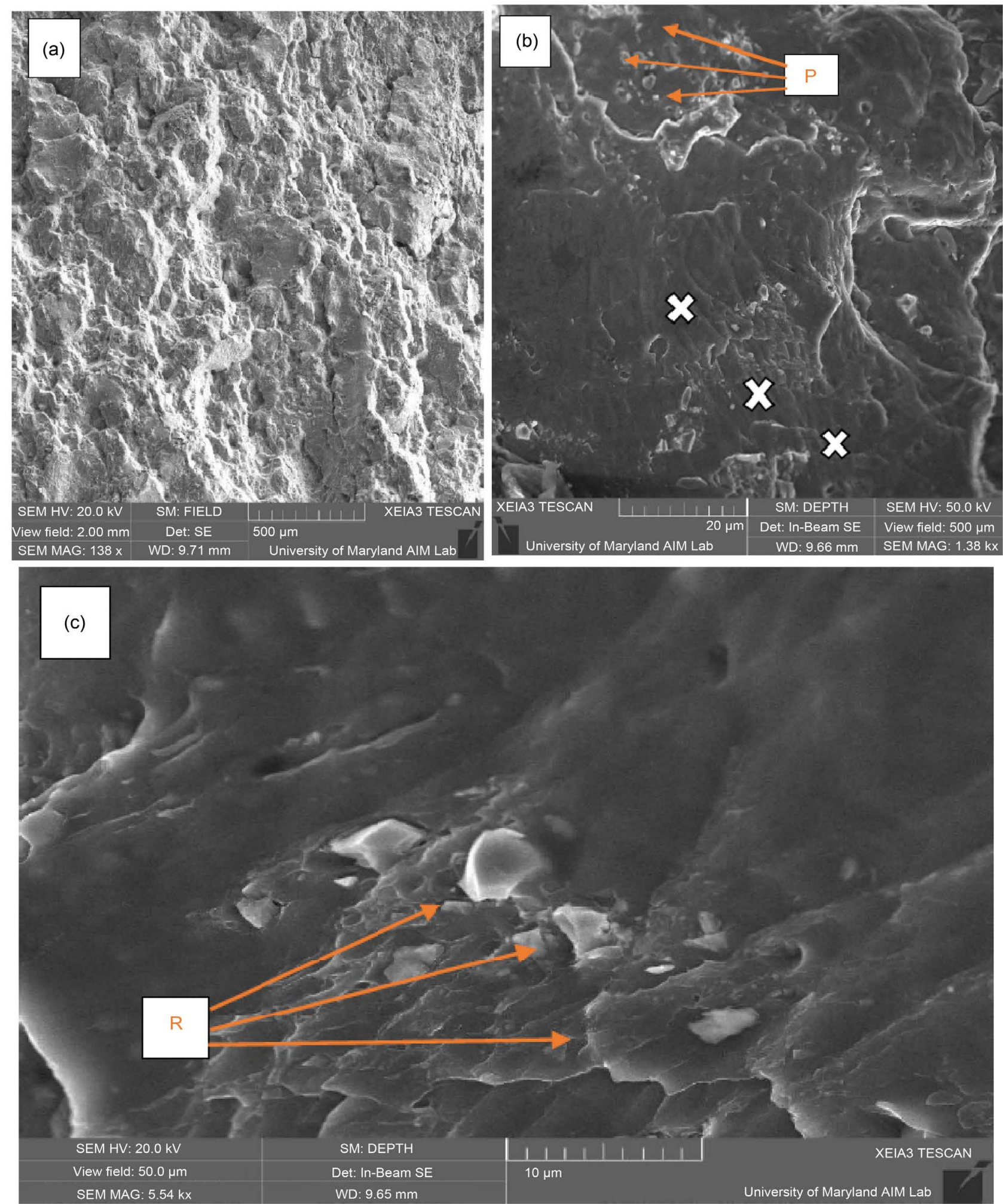

Figure 5. SEM Fatigue fracture surface of AA 2519-T8 (a) Magnification: 138x, (b) Magnification: 1.38 kx, and (c) Magnification: $5.54 \mathrm{kx}$.

microvoids but very limited when compared to that of AA 2219-T8 in Figures $4(\mathrm{a})-(\mathrm{c})$. The presence of some secondary phase particles in AA 2519-T8 is also 

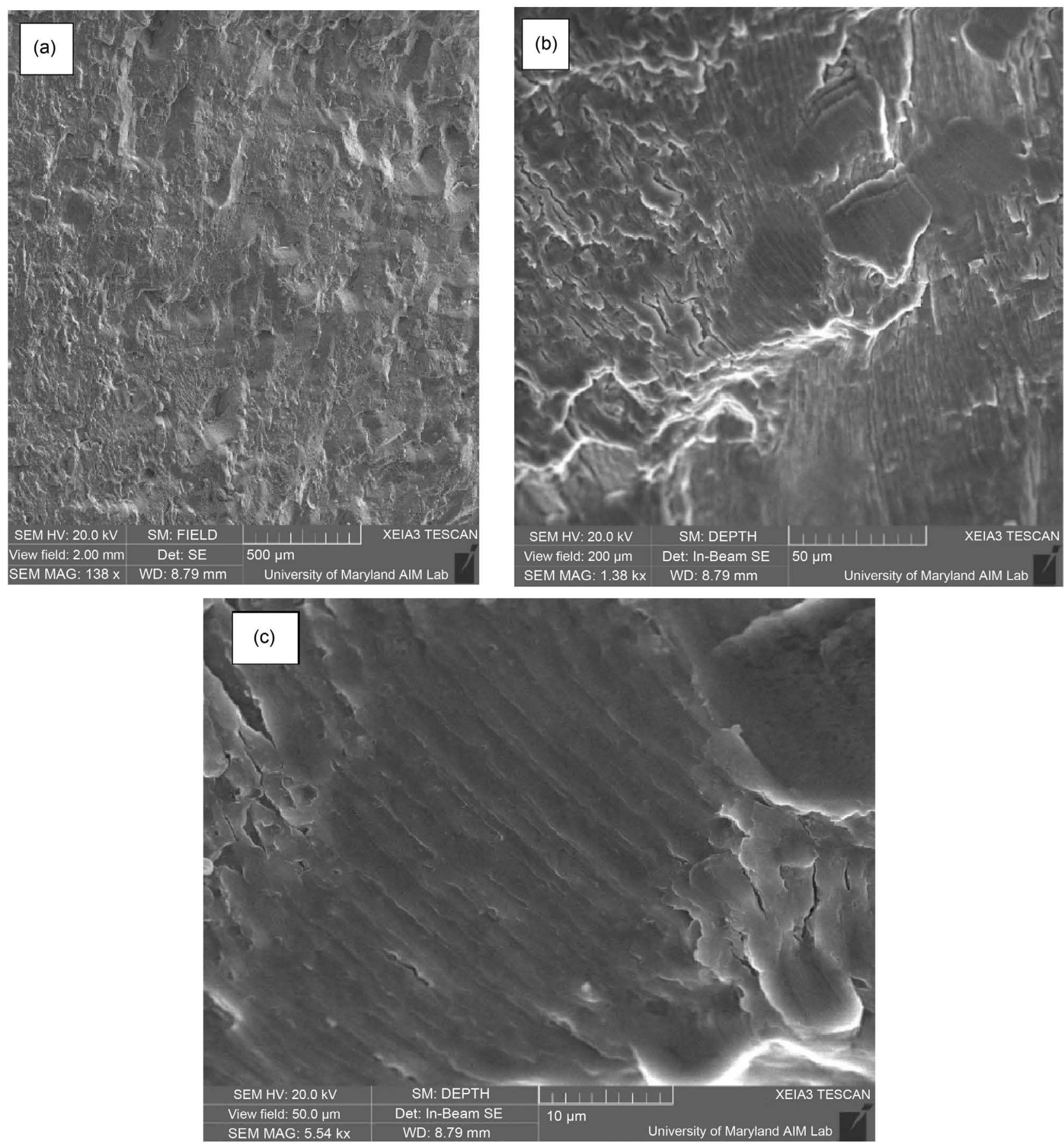

Figure 6. SEM Fatigue fracture surface of AA 2624-T351 (a) Magnification: 138x, (b) Magnification: 1.38 kx, and (c) Magnification: $5.54 \mathrm{kx}$.

observed in the vicinity of striations (Figure 5(c)) and these features are found more significant at the region $\mathrm{R}$ of the fracture surface. Microvoids are observed but relatively scanty. The fracture surface features of AA 2519-T8 as observed in Figures 5(a)-(c) showed high resistance to fatigue cracks nucleation and growth in comparison with AA 2219-T8. Although the features depicted dual failure mechanisms (ductile and brittle failure), failure due to ductile was found to be 
predominant.

Very fine fatigue striations can be observed on the fracture surface of AA 2624-T351 (Figure 6(a) and Figure 6(b)). The observed microvoids can be considered insignificant relative to the bulk microstructure. Unlike in the case of AA 2519-T8 alloy where secondary particles are observed in the vicinity of striations (Figure 5(a) and Figure 5(b)), the presence of these particles along the striations pattern are not obvious in the fracture surface of AA 2624-T351. In addition, Figure 5(c) shows an array of very fine fatigue striations to be predominant on the fracture surface of this alloy. The presence of microvoids and microcracks features can be considered insignificant in AA 2624-T351 (Figures 6(a)-(c)) relative to AA 2219-T8 (Figures 4(a)-(c)) and AA 2519-T8 (Figures 5(a)-(c)). The fracture features generally observed in Figures 6(a)-(c) implies highly significant ductile failure mechanism and high resistance to fatigue cracks nucleation and propagation in AA 2624-T351 when compared to AA 2219-T8 and AA 2519-T8 aluminum alloys.

\section{Conclusions}

The fatigue response of smooth specimens of AA 2219-T8, AA 2519-T8 and AA 2624-T351 were investigated in this work. Three different alloys of AA 2000 aluminum series were tested under quasi-static tensile and uniaxial fatigue loads. Fractographic examinations were also carried out to understand the failure and fracture mechanisms of the alloys. The tensile test results show that AA 2219 has the lowest strength, with an ultimate tensile strength that is $65 \%$ less than that of the other two alloys. The fatigue results show significant differences in the fatigue lives of the three alloys with AA 2219-T8 having the lowest fatigue life and AA 2624-T351 with the highest fatigue life at the same stress amplitude.

The following specific conclusions are drawn from this study:

1) The fracture morphologies of AA 2219-T8 indicate ductile and brittle failure modes. The coalescence of micropores, microvoids, particles cleavage, microcracks and random intermix is indication of low resistance to fatigue cracks initiation and growth. The features strongly revealed brittle and transgranular fracture.

2) The fracture surface of AA 2519-T8 depicted high resistance to fatigue cracks nucleation and propagation when compared to AA 2219-T8. Dual failure mechanisms (ductile and brittle failure) are observed. However, ductile fracture failure was however found to be predominant.

3) The AA 2624-T351 fracture surface features implied highly significant ductile failure mechanism and revealed higher resistance to fatigue cracks nucleation and propagation in comparison to AA 2219 and AA 2519 aluminum alloys.

Future study will focus on obtaining data for plotting the complete S-N curves for each alloy. To attain such data, tests will be conducted in several samples of each alloy over a range of nominal stresses. Future study will also include the effect of thermal treatments on the microstructure and fatigue responses of these 
alloys.

\section{Acknowledgements}

Financial support for this work was provided by DoD through contract \# W911NF-15-1-0457 under the direct supervision of Patricia Huff (HBCU/MI Program Manager, ARO).

\section{Conflicts of Interest}

The authors declare no conflicts of interest regarding the publication of this paper.

\section{References}

[1] Strivatsan, T.S., Vasudevan, S., Park, L. and Lederich, R.J. (2008) The Quasi-Static Deformation and Final Fracture Behaviour of Aluminum Alloy 2219. Materials Science and Engineering. A, 497, 270-277.

https://doi.org/10.1016/j.msea.2008.07.033

[2] Alexopoulos, N.D., Migklis, E., Stylianos, A. and Myriounis, D.P. (2013) Fatigue Behaviour of the Aeronautical Al-Li (2198) Aluminum Alloy under Constant Amplitude Loading. International Journal of Fatigue, 56, 95-105. https://doi.org/10.1016/j.ijfatigue.2013.07.009

[3] Guerin, M., Alexis, J., Andrieu, E., Blanc, C. and Odemer, G. (2015) Corrosion-Fatigue Lifetime of Aluminium-Copper-Lithium Alloy 2050 in Chloride Solution. Materials \& Design, 87, 681-692. https://doi.org/10.1016/j.matdes.2015.08.003

[4] Sayuti, M., Ahmed, A.D. and Handi, S.M. (2013) An Investigation of Optimum $\mathrm{SiO}_{2}$ Nanolubrication Parameters in End Milling of Aerospace Al6061-T6 Alloy. International Journal of Advanced Manufacturing Technology, 67, 833-849. https://doi.org/10.1007/s00170-012-4527-z

[5] Li, H. and Lu, X. (2015) Springback and Tensile Strength of 2A97 Aluminium Alloy during Age Forming. Transactions of Nonferrous Metals Society of China, 25, 1043-1049. https://doi.org/10.1016/S1003-6326(15)63696-2

[6] Bobbili, R., Madhu, V. and Gogia, A.K. (2016) Tensile Behaviour of Aluminium 7017 Alloy at Various Temperatures and strain Rates. Journal of Materials Research and Technology, 5, 190-197. https://doi.org/10.1016/j.jmrt.2015.12.002

[7] Pourbahari, B. and Emamy, M. (2016) Effects of La Intermetallics on the Structure and Tensile Properties of Thin Section Gravity Die-Cast A 357 Al Alloy. Materials \& Design, 94, 111-120. https://doi.org/10.1016/j.matdes.2016.01.039

[8] Cadoni, E., Dotta, M., Forni, D. and Kaufmann, H. (2017) Tensile Behavior of Commercial Aluminium Alloys Used in Armour Applications at High Strain Rate. Procedia Engineering, 197, 168-175. https://doi.org/10.1016/j.proeng.2017.08.093

[9] Graham, W.R., Hall, C.A. and Morales, M.V. (2014) The Potential of Future Aircraft Technology for Noise and Pollutant Emissions Reduction. Transport Policy, 34, 36-51. https://doi.org/10.1016/j.tranpol.2014.02.017

[10] Tsai, W., Chang, Y., Li, S., Chei, H. and Chu, P. (2014) A Green Approach to the Weight Reduction of Aircraft Cabins. Journal of Air Transport Management, 40, 65-77. https://doi.org/10.1016/j.jairtraman.2014.06.004

[11] Huang, R., Riddle, M., Graziano, D., Warren, J., Das, S., Nimbalkar, S., Cresko, J. and Masanet, E. (2016) Energy and Emissions Saving of Additive Manufacturing: 
The Case of Lightweight Aircraft Components. Journal of Cleaner Production, 135, 1559-1570. https://doi.org/10.1016/j.jclepro.2015.04.109

[12] Bruekner, J.K. and Abreu, C. (2017) Airline Fuel Usage and Carbon Emissions: Determining Factors. Journal of Air Transport Management, 62, 10-17. https://doi.org/10.1016/j.jairtraman.2017.01.004

[13] Xue, Y., Kadiri, H.E., Horsfemeyer, M.F., Jordan, J.B. and Weiland, H. (2007) Micromechanism of Multistage Fatigue Crack Growth in a High-Strength Aluminum Alloy. Acta Materialia, 55, 1975-1984. https://doi.org/10.1016/j.actamat.2006.11.009

[14] Gupta, V.K. and Agnew, S.R. (2011) Fatigue Crack Surface Crystallography near Crack Initiating Particle Clusters in Precipitation Hardened Legacy and Modern Al-Zn-Mg-Cu Alloys. International Journal of Fatigue, 33, 1159-1174. https://doi.org/10.1016/j.ijfatigue.2011.01.018

[15] Carpio, F.J., Araujo, D., Pacheco, F.J., Mendez, D., Garcia, A.J., Villar, M.P., Garcia, R., Jimenez, D. and Rubio, L. (2003) Fatigue Behaviour of Laser Machined Aluminium Alloy. Applied Surface Science, 208-209, 194-198. https://doi.org/10.1016/S0169-4332(02)01369-7

[16] Desmukh, M.N., Pandey, R.K. and Mukhopadhyay, A.K. (2005) Fatigue Behavior of 7010 Aluminum Alloy Containing Scandium. Scripta Materialia, 52, 645-650. https://doi.org/10.1016/j.scriptamat.2004.11.018

[17] Wang, Q.Y., Kawagoishi, N. and Chen, Q. (2006) Fatigue and Fracture Behaviour of Structural Al-Alloys up to Very Long Life Regimes. International Journal of Fatigue, 28, 1572-1576. https://doi.org/10.1016/j.ijfatigue.2005.09.017

[18] Ceschini, L., Morri, A. and Sambogna, G. (2008) The Effect of Hot Isostatic Pressing on the Fatigue Behaviour of Sand-Cast A356-T6 and A204-T6 Aluminum Alloys. Journal of Materials Processing Technology, 204, 231-238. https://doi.org/10.1016/j.jmatprotec.2007.11.067

[19] Sharma, V.M.J., Kumar, K.S., Rao, B.N. and Pathak, S.D. (2011) Fatigue Crack Growth of AA2219 under Different Aging Conditions. Materials Science and Engineering: $A$, 528, 4040-4049. https://doi.org/10.1016/j.msea.2011.01.055

[20] Zheng, Z.Q., Cai, B., Zhai, T. and Li, S.C. (2011) The Behavior of Fatigue Crack Initiation and Propagation in AA2524-T34 Alloy. Materials Science and Engineering: $A$, 528, 2017-2022. https://doi.org/10.1016/j.msea.2010.10.085

[21] Ma, Y.E., Zhao, Z., Liu, B. and Li, W. (2013) Mechanical Properties and Fatigue Crack Growth Rates in Friction Stir Welded Nugget of 2198-T8 Al-Li Alloy Joints. Materials Science and Engineering: A, 569, 41-47. https://doi.org/10.1016/j.msea.2013.01.044

[22] Yan, L. and Fan, J. (2016) In-Situ SEM Study of Fatigue Crack Initiation and Propagation Behavior in 2524 Aluminum Alloy. Materials \& Design, 110, 592-601. https://doi.org/10.1016/j.matdes.2016.08.004

[23] Shou, W.B., Yi, D.Q., Liu, H.Q., Tang, C., Sheu, F.H. and Wang, B. (2016) Effect of Grain Size on the Fatigue Crack Growth Behavior of 2524-T3 Aluminum Alloy. Archives of Civil and Mechanical Engineering, 16, 304-312. https://doi.org/10.1016/j.acme.2016.01.004

[24] Wu, W., Liu, Z., Bai, S., Li, F., Liu, M. and Wang, A. (2017) Anisotropy in Fatigue crack Propagation Behavior of Al-Cu-Li Alloy Thick Plate. Materials Characterization, 131, 440-449. https://doi.org/10.1016/j.matchar.2017.07.025

[25] Ovono, D.O., Guillot, I. and Massinon, D. (2008) Study on Low-Cycle Fatigue Behaviours of the Aluminium Cast Alloys. Journal of Alloys and Compounds, 452, 425-431. https://doi.org/10.1016/j.jallcom.2006.11.052 
[26] Takahashi, Y., Shikama, T., Yoshihara, S., Aiupa, T. and Noguchi, H. (2012) Study on Dominant Mechanism of High-Cycle Fatigue Life in 6061-T6 Aluminum Alloy through Microanalyses of Microstructurally Small Cracks. Acta Materialia, 60, 2554-2567. https://doi.org/10.1016/j.actamat.2012.01.023

[27] Sivaraj, P., Kanagarajau, D. and Balasubramanian, V. (2014) Fatigue Crack Growth Behaviour of Friction Stir Welded AA7075-T651 Aluminium Alloy Joints. Transactions of Nonferrous Metals Society of China, 24, 2459-2467.

https://doi.org/10.1016/S1003-6326(14)63371-9

[28] Aboulkair, N.T., Maskery, I., Tuck, C., Ashcraft, I. and Everitt, N.M. (2016) Improving the Fatigue Behaviour of Selectively Laser Melted Aluminium Alloy. Influence of Heat Treatment and Surface Quality. Materials \& Design, 104, 174-182. https://doi.org/10.1016/j.matdes.2016.05.041

[29] Szusta, J. and Sewryn, A. (2017) Experimental Study of the Low-Cycle Fatigue Life under Multiaxial Loading of Aluminum Alloy EN AW-2024-T3 at Elevated Temperatures. International Journal of Fatigue, 96, 28-42. https://doi.org/10.1016/j.ijfatigue.2016.11.009

[30] Wang, J.T., Zhang, Y.K., Chen, J.F., Zhou, J.Y., Luo, K.Y., Tan, W.S., Sun, L.Y. and Lu, Y.L. (2017) Effect of Laser Shock Peening on the High-Temperature Fatigue Performance of 7075 Aluminum Alloy. Materials Science and Engineering. A, 704, 459-468. https://doi.org/10.1016/j.msea.2017.08.050

[31] Strivatsa, T.S., Kolar, D. and Magnusen, P. (2002) The Cyclic Fatigue and Final Fracture Behaviour of Aluminum Alloy. Materials \& Design, 23, 129-139. https://doi.org/10.1016/S0261-3069(01)00070-X

[32] Giummarra, C., Bray, G.H. and Duquette, D.J. (2006) Fretting Fatigue in 2XXX Series Aerospace Aluminium Alloys. Tribology International, 39, 1206-1212. https://doi.org/10.1016/j.triboint.2006.02.010

[33] Fersini, D. and Pirondi, A. (2007) Fatigue Behavior of Al2024-T3 Friction Stir Welded Lap Joints. Engineering Fracture Mechanics, 74, 468-480. https://doi.org/10.1016/j.engfracmech.2006.07.010

[34] Malarvizhi, S., Raghukandan, K. and Viswanathan, N. (2008) Fatigue Behaviour of Post Weld Heat Treated Electron Beam Welded Aluminum Alloy Joints. Materials \& Design, 29, 1562-1567. https://doi.org/10.1016/j.matdes.2007.11.005

[35] Menzemer, C.C., Azzan, D. and Strivatsan, T.S. (2010) A Study of Fatigue and Fracture Response of Cantilevered Luminaire Structures Made from Aluminum Alloy 6063. Materials Science and Engineering: A, 527, 4680-4686. https://doi.org/10.1016/j.msea.2010.03.085

[36] Priet, B., Odemer, G., Blanc, C., Giffard, K. and Arurault, L. (2016) Effect of New Sealing Treatments on Corrosion Fatigue Lifetime of Anodized 2024 Aluminium Alloy. Surface and Coatings Technology, 307, 206-219. https://doi.org/10.1016/j.surfcoat.2016.07.083

[37] Fitzka, M. and Mayer, H. (2016) Constant and Variable Amplitude Fatigue Testing of Aluminum Alloy 2024-T351 with Ultrasonic and Servo-Hydraulic Equipment. International Journal of Fatigue, 91, 363-372. https://doi.org/10.1016/j.ijfatigue.2015.08.017

[38] Skorupa, M., Machniewicz, T., Skorupa, A. and Korbel, A. (2016) Fatigue Life Predictions for Riveted Lap Joints. International Journal of Fatigue, 94, 41-57. https://doi.org/10.1016/j.ijfatigue.2016.09.007

[39] Huang, Y., Li, H., Yang, X., Guan, Z., Li, Z. and Sun, Y. (2017) Improving the Fatigue Life of 2297-T87 Aluminum-Lithium Alloy Lugs by Cold Expansion, Interfe- 
rence Fitting, and their Combination. Journal of Materials Processing Technology, 249, 67-77. https://doi.org/10.1016/j.jmatprotec.2017.06.004

[40] Xu, L., Yu, X., Hui, L. and Zhou S. (2017) Fatigue Prediction of Aviation Aluminium Alloy Based on Quantitative Pre-Corrosion Damage Analysis. Transactions of Nonferrous Metals Society of China, 27, 1353-1362. https://doi.org/10.1016/S1003-6326(17)60156-0

[41] Hemmouche, L., Fares, C. and Belouchrani, M.A. (2013) Influence of Heat Treatment and Anodization on Fatigue Life of 2017A Alloy. Engineering Failure Analysis, 35, 554-561. https://doi.org/10.1016/j.engfailanal.2013.05.003

[42] Hao, H., Ye, D. and Chen, C. (2014) Strain Ratio Effects on Low-Cycles Fatigue Behaviour and Deformation Microstructure of 2124-T851 Aluminum Alloy. Materials Science and Engineering: A, 605, 151-159. https://doi.org/10.1016/j.msea.2014.03.040

[43] Fares, C., Hemmouche, L., Belouchrani, M.A., Amrouche, A., Chicot, D. and Puchi-Cabrera, E.S. (2015) Coupled Effects of Substrate Microstructure and Sulphuric Acid Anodizing on Fatigue Life of a 2017A Aluminum Alloy. Materials \& Design, 86, 723-734. https://doi.org/10.1016/j.matdes.2015.07.120

[44] Stanley, D., Twerbuch, J., Tan, T. and Anasori, B. (2016) Reconstruction of Fatigue Crack Growth in AA2024-T3 and AA2198-T8 Fastened Lap Joints. Theoretical and Applied Fracture Mechanics, 82, 33-50. https://doi.org/10.1016/j.tafmec.2015.06.006

[45] Jayaraman, N., Prevey, P. and Mahoney, M. (2003) Fatigue Improvement of Aluminum Alloy FSW with Low Plasticity Burnishing. Proceedings of the $132 \mathrm{nd}$ TMS, San Diego, CA, 2-6 March 2003, 1-10.

[46] Xu, W.F., Liu, J.H., Chen, D.L. and Luan, G.H. (2014) Low-Cycle Fatigue of a Friction Stir Welded 2219-T62 Aluminum Alloy at Different Welding Parameters and Cooling Conditions. International Journal of Advanced Manufacturing Technology, 74, 209-218. https://doi.org/10.1007/s00170-014-5988-Z

[47] ASTM E466-15 (2015) Standard Practice for Conducting Force Controlled Constant Amplitude Axial Fatigue Tests of Metallic Materials. ASTM International, West Conshohocken, PA.

[48] ASTM E606/E606M-12 (2012) Standard Test Method for Strain-Controlled Fatigue Testing. ASTM International, West Conshohocken, PA.

[49] Tang, K.K., Wu, H. and Berto, F. (2015) Fatigue Data Interpretation of 7075-T6 Al Sheets by Energy Density Factor in a Dual Scale Model. Theoretical and Applied Fracture Mechanics, 79, 98-104. https://doi.org/10.1016/j.tafmec.2015.06.012

[50] Rambabu, P.R., Narasayya, C.V.A., Mohan, M.K. and Prasad, N.E. (2015) Mixed Mode (I/III) Fracture Behaviour of an Aerospace Grade Aluminium Alloy in Different Ageing Conditions. Materials Today. Proceedings, 2, 1741-1746. https://doi.org/10.1016/j.matpr.2015.07.008 